\title{
PROFISSÕES LIBERAES
}

\section{O ASSUMPTO}

Em meu modesto opusculo "Quarenta Annos de Vida Forense", occupei-me com o excesso de advogados. Neste artigo vou dar mais vasta área ás minhas investigações, tractando das condições de todos os profissionaes que vivem da sciencia, particularmente da Medicina, do Direito e da Engenharia, bem como dos que fazem profissão das bellas artes, notadamente de poesia, musica e pintura. Não é possivel, creio, pôr em seus devidos termos o difficil e complexo problema da concurrencia em profissões liberaes, nem indicar a solução que lhe deve ser dada, sem que seja a materia encarada de um ponto mais alto, que o dado á pessoa posta dentro de certa classe de especialistas com um circulo visual muito estreito. Prova disto encontra-se na celebre obra de Calamandrei "Troppi avvocati" Mostra o autor a triste situação economica somente de seus compatriotas que exercem a advocacia, mas não consegue, nem conhecer as verdadeiras causas do mal, nem encontra para elle remédio. Meu intuito naturalmente é buscar remedio á calamidade que afflige aos bachareis em Direito, mas, para isto, cumpre investigar em todas as profissões liberaes, quaes as suas raizes, qual a sua origem, quaes as suas causas. $\mathrm{O}$ problema parece muito mais serio do que se afigurou a muitos dos que com elle se occuparam. Os processos indicados para a reducção do numero dos bachareis em Direito são insufficientes para ser obtido resuliado sensivel E' entretanto essa diminuição, difficil de alcançar, o unico meio de enfrentar a questão. 


\section{EXISTENCIA DO PROBLEMA}

E' admiravel haver quem negue existir um excesso de profissionaes nas carreiras liberaes. Ha o asserto "directo. dizer que são ainda poucos os medicos, advogados e engenheiros, particularmente engenheiros em um paiz novo como. é o nosso! Só quem é capaz de negar a luz meridiana tem animo para tal affirmar $\mathrm{O}$ numero de bachareis desoccupados e na mais negra miseria, não só nesta capital, mas em todo o interior do paiz é assombroso Já não causa extranheza o que se denomina atravessamento de trabalho, nem a concurrencia pelo preço vil, a que os francezes denominam "gâter le métier". Basta um passeio pelas ruas desta capital para ter-se, pelo encontro de innumeros medicos, engenheiros e advogados, vencidos na vida, idéa dos effeitos da concurrencia em carreiras em que ha excesso de profissionaes. Sophisma ridiculo é dizer, processo indirecto, para justificar a plethora, que uma carta não occupa logar. Occupa sim, e só a audacia dos interessados pode arrastar os espiritos menos cultos e pouco observadores a compartir esta opinião. Em um conhecido romance, premiado em França, "La Martenelle", figura o autor a tristissima posição de quem teve estudos em escola destinacia a formar professoras. Até louco será considerado o bacharel que se apresentar a um negociante pedindo-lhe um emprego no balcão. Em boa fé, ninguem poderá contestar que a carta de bacharel fecha a entrada para os empregos que não sejam considerados nobres em nossa sociedade, onde os preconceitos dominam, e dominarão. As proprias pessoas sensatas, os homens superiores a taes opiniões vulgares, não poderão fugir a uma injusta suspeita de incapacidade contra o homem formado que não poude conseguir prover a sua subsistencia por meio dos conhecimentos adquiridos na Faculdade. Quando assim não seja, quando tenham razão os que entendem que não occupa logar o titulo de bacharel em Direito, poderão contestar que o tempo de es- 
tudo foi perdido pelo individuo que não tirará proveito de seu curso? Não seria muito mais proveitoso que tivesse applicado o estudante seu tempo em estudos mais convenientes para a carreira mercantil ou de industria fabril? Tenham todos deante de si que a vida é muito curta. "ars longa, vita brevis.

\section{A GRAVIDADE DO PROBLEMA}

Desde a mais remota antiguidade, exerceram as profissões liberaes uma verdadeira fascinação sobre os homens. Quero remontar ao Egypto. Da obra de Malet “L'Antiquité", tiro algumas informações sobre o escriba. Diz o historiador: "Era escriba quem tinha estudado, quem sabia ler, escrever e fazer as contas... Elle percebia impostos; vigiava os canteiros, recrutava e armava os soldados. Era contramestre, engenheiro, recebedor de contribuições, sacerdote, general, segundo suas aptidões, successo nos exames ou fortuna. Zombava do ferreiro sempre á boca do forno; do talhador de pedras constantemente curvado e com a espinha dorsal dorida, do barbeiro que mendiga a clientela de casa em casa, do tecelão, do tintureiro, cujos dedos têm o mau cheiro do peixe podre; do sapateiro

Seu desprezo pelas demais profissões se manifesta nas seguintes palavras: "Observei os trabalhos mecanicos, dizia um escriba a seu filho, e conclui que, de facto, acima das letras nada existe. Por isto faço-te amar a literatura, tua verdadeira mãe; tracto de conseguir que entrem suas bellezas em tua cabeça Ella é a mais importante de todas as profissões; quem tirou della proveito desde sua mocidade é considerado." Diz Malet que, por isto mesmo, se impunham os egypcios os maiores sacrificios, do mesmo modo que os chinezes, para conseguirem a approvação de seus $f_{1-}$ lhos em exames de escribas (L'Antiquité, pags, 21 e 22) Poderia dizer o historiador francez "os mesmos sacrificios que os francezes e os portuguezes se impunham para terem 
um padre na familia" Da aristocratica Roma, apresenta Cogliolo noticia em relação aos jurisconsultos. Era uma classe de nobres. Considerava-se vergonhoso em Roma que um gentilhomem não entendesse o que se referia ao Direito. Lembra Cogliolo o succedido a Servio Sulpicio, quando consultou a Quinto Mucio (Fil., pag. 81), facto memorado no Digesto (de or. jur., fr. $2 \S 43$ ) $\mathrm{Na}$ Grecia, menos valor parece ter tido o exercicio das profissões liberaes, com excepção da oratoria, das bellas artes, que constituiam os encantos daquelle povo artistico, e dado ás dispatas philosophicas e politicas. Como é sabido, e por Ihering repetido, os rhetoricos gregos appareciam em Roma avidos de dinheiro, embora trazendo grande riqueza literaria na cabeça

Muito vária tem sido a importancia do homem de letras nas diversas epochas.

A Mark Twain, cidadão da livre republica dos Estados Unidos da America, se afigurou repugnante a baixeza revelada pelos pintores italianos nos quadros com que conquistaram a immortalidade. Não se lembrava o critico de que a fome é má conselheira, e, por isto, não perdoou aos infelizes a bajulação aos poderosos da epocha sinistra em que os despotas dispuzeram da sorte da bella terra de Garibaldi.

Cogliolo, de cuja autoridade acima me vali, dá um quadro da importancia que teve o jurisconsulto em Roma, onde, além da funcção expressa pela trilogia do respondere, scribere et cavere, tinha por missão aconselhar no que havia mais intimo na familia, e assim, por exemplo, de fiiia collocanda, de fundo emendo, de agro colendo, de omni denique aut officio aut negotio" Ajunta tristemente o grande mestre italiano que hoje representam, não raro, os advogados o papel de baixos leguleios, occupam-se de transacções, mutuos, locações e outros negocios. Direi que até mesmo um elevado numero de practicos, que entendem ser advogados zelosos da causa publica unida aos interesses do clien- 
te, que se julgam habeis sacerdotes do Direito, não passam de pescadores de arestos, a verem o que representa o actual modo de pensar do tribunal, afim de com elle tirar proveito para o pleito que defendem, sem indagarem si este representa ou não, o que é justo e proveitoso á sociedade. Tempo houve em que poucos eram os advogados que diziam, do mesmo modo que Lobão, ser a sua consciencia a do juiz no ultimo julgado. Revistas de critica dos julgados têm vida ephemera, porque poucos são os que tomam a profissão como sendo um sacerdocio, e que julgam que, ao defender o direito do cliente, devem ter sempre deante de si o interesse da sociedade.

Querendo, neste tempo em que o determinismo economico dominou, tirar da profissão proveito pecuniario. sendo ésta a idéa fixa de quasi todos os homens que se formam, e sendo, por outro lado, pequenissimo o numero dos que medram nas profissões liberaes, podendo até dizer-se que constituem uma insignificante minoria, traçado está 0 caminho a ser seguido pelos avidos de ganho, seja por que titulo for" seguem o "honestly, if you can, but make money" Eis como se precipitam no abysmo da deshonra tantos homens que, em outras profissões nas quaes não fossem urgidos pela necessidade, teriam seguido sempre 0 recto caminho do dever.

A idéa fixa de ganhar dinheiro anichou-se em quasi todos os cerebros, e quem me ler essas rapidas observações poderá facilmente disto se convencer com a seguinte experiencia. Exponha a qualquer pessoa a nobreza da profissão, faça uma apologia do estudo do Direito, mostre que um jurisconsulto tem probabilidade de encontrar abertas todas as portas, de aspirar a tudo, que pode, com facilidade maior que outro qualquer profissional, chegar a chefe de Estado, borde sobre essa talagarça que nos iransmittiram os seculos na phrase "dat Justinianus honores", e é quasi certo que o interlocutor lhe interromperá o discurso como esta replica. "E, numa boa causa, si tiver sorte, pode 
fazer fortuna! "Sem um curso penoso, tambem o que compra um bilhete de loteria, si tiver sorte, pode fazer fortuna.

\section{OS MODESTOS}

Ha os profissionaes modestos, que se contentam com a aurea mediocritas. Quando advogados, seguirão o rumo. que lhes traça Calamandrei. Diz o illustre jurisconsulto italiano que não é funcção do advogado vencer sempre, mas esclarecer o pleito, e esse serviço elle o presta expondo ao juiz a especie sem as circumstancias inuteis para a solução do caso, investigando o principio de Direito applicavel ao ponto em discussão, e finalmente mostrando a solução mais proveitosa para a sociedade. Assim agindo, é o advogado um auxiliar valiosissimo para o Juiz. Poupa-lhe o advogado o trabalho de ouvir das partes a exposição do ponto em discussão, com rodeios inuteis, evita-lhe a procura nos livros das regras de Direito que devem reger a especie, graças á exposição que faz do que dizem da especie mestres e lei, tudo sob a critica do patrono da parte contrária, e finalmente esclarece o Magistrado acerca das necessidades sociaes.

Mas estes mesmos advogados frequentemente são infelizes em sua profissão, si não tiverem, ao lado do desempenho dessa nobre funcção, a cautela de procurarem o que é corrente e vencido na praxe, na practica de julgar $\mathrm{Ha}$ pouco, com o intuito de acudir por um remédio efficaz á morosidade dos juizes, houve quem se lembrasse de lhes dar um auxiliar para lhes fazer relatorio do processo: esqueceu-se de que este ajudador é: o advogado. Com effeito, ha a tendencia para ser mantido o que decidiu uma vez, e a autoristas rerum perpetuo similiter judicatarum é uma força contra a qual não pode luctar o profissional que deve viver do officio. Dahi a necessidade em que elle se encontra de buscar, o que com frequencia tem sido acceito pelos juizes, e, com a continuação, conforma-se o práctico com 
todos os erros tradicionaes Forma-se então o aresteiro que cada vez menos critica o consagrado pela praxe, já por desanimo, já por notar que aos magistrados repugna qualquer augmento de trabalho mental, e, pela lei do minimo esforço, querem ficar no adoptado anteriormente.

Este é o advogado que não pretende fazer fortuna, mas que deseja, sem ambição e obscuradamente, viver de sua profissão. Uma vez assim constituida a sociedade pelo aspecto da vida forense, é claro que, nas Faculdades, pouca vontade haverá da parte da maioria dos alumnos de estudar a fundo a sciencia.

Nas outras carreiras, na diplomacia, na politica, e emfim na magistratura, a erudição é de valor insignificantissimo Nenhum interesse pois ha em, como diziam nossos avós, queimar o estudante as pestanas, curvado sobre os livros. Outros; que não o estudo, serão os factores de sua fortuna. Eis o motivo da decadencia do estudo do Direito, phenomeno que terá consequencias fataes para a patria em futuro não muito remoto

\section{OS REMEDIOS}

O mal não é só do Brasil, mas da Italia e da França, sendo mesmo provavel que em outros logares se tenha feito sentir Gide sustenta que o problema existe em todas as sociedades cultas. Eis suas palavras: "A verdade é que, si toda profissão pode ser util nos limites das necessidades, torna-se nociva desde que passa ao excesso, porque degenera em parasitismo. O que é preciso é uma justa proporção, entre o effectivo de cada grupo profissional e a importancia da necessidade que elle deve satisfazer Ora, infelizmente, este justo equilibrio está longe de ser realizado em nossas snciedades civilizadas" (I/157) Em nota, traz uma estatistica das pessoas empregadas nos varios ramos de trabalhos sociaes, fazendo sentir que um quinto da população se entrega ás profissões liberaes, ao commercio e ao serviço 
domestico, quando só o resto se occupa com a agricultura e a industria, que são as profissões directamente productivas. $\mathrm{O}$ ensino profissional indicado pelo mestre para desviar das profissões parasitarias, é, como reconhece, summamente difficil de ser ministrado. Entre outras difficuldades, põe o grande economista em destaque a circumstancia de, ministrado nas escolas, dever ser completado nas officinas (1/174) Propõe todavia a aprendizagem obrigatoria entre 13 e 14 annos. Si é realmente difficil o encargo de habilitar o moço á escolha de uma profissão util a elle mesmo. e á sociedade, não é menos certo que alguma coisa se deveria ter tentado a este respeito, e a verdade é que infelizmente os Estados têm deixado isto em completo esquecimento Abandonar porém ao criterio e á capacidade (ou incapacidade) dos paes o que estes denominam "aprender um officio", eis o que é entregar-lhes missão muito acima de suas forças: não encontram mestres que se prestem ao. ensino, limitando-se estes, as mais das vezes, a aproveitar-se do trabalho do discipulo, e guardar occultos, quanto possivel, os segredos da profissão, temerosos de crearem um concurrente mais habil no alumno, e, quando assim não seja, pelo menos nenhuma vantagem auferem com o progresso do moço Uma vez com conhecimentos geraes na aprendizagem, acha-se o moço em estado de consultar as proprias inclinações, e ver qual o ramo de actividade que mais se coaduna com a sua vocação, e entrará no estudo especial de uma profissão. Ao que Gide diz, devo ajuntar, de passo, um facto de que tenho conhecimento por informações industriaes, e é: que, em materia de educação profissional do operario francez, a patria de Gide não tem progredido: pelo contrario. está em regresso.

Sem duvida é um derivativo importante do estudo das artes liberaes a instituição regular das escolas profissionaes. Considere-se que um rapaz de média fortuna só encontra, hoje, em nossa patria, dois ramos de actividade que 
condizem com a sua posição: o commercio e as profissões. liberaes. Não está em condições de dirigir uma industria, por ignorar os segredos della. Nem mesmo na agricultura poderá ser um chefe de serviços, salvo na agricultura extractiva practicada ainda em grande parte no nosso solo. Uma vez dotado de conhecimentos nestes ramos importantissimos de profissões directamente productivas, poderá ser o auxiliar valiosissimo dos capitalistas, que precisam de quem superintenda o trabaiho em suas emprezas. E' certo que temos algumas escolas agricolas, mas estas estão longe de darem os profissionaes versados em todos os trabalhos desse ramo de actividade.

Como acabo de fazer sentir, o mais efficaz remedio. derivativo das universidades é a escola em que se ministre o ensino profissional, habilitando alguns a serem operarios destrissimos em seu modesto labor, e outros a poderem dirigir, com proveito para os capitalistas, as officinas, os estabelecimentos industriaes.

Peço licença para uma observação. Hoje ninguem mais acredita na tão decantada inutilidade da pericia do operario, sob pretexto de que foi elle substituido pela machina. As machinas deram muito menos do que se pensava. Gide o affirma, e é fóra de duvida que, ainda para as manejar, necessita o homem ter certa cultura, tão importante quanto a que era exigida para o trabalho manual, e quiçá maior

$\mathrm{Na}$ Italia, segundo Nitti, o problema é tambem muitissimo serio, affirmando o illustre mestre, em uma erudita nota de seu tratado de Finanças (n. ${ }^{\circ}$ 149, pag. 479, ed. franceza de 1904), ser sua patria o paiz em que ha maior parasitismo. A plethora nas escolas onde se estudam artes liberaes, a par da carencia de alumnos nas technicas, é phenomeno impressivo, segundo o notavel escriptor. Dá como sendo unico remedio a adoptar uma propaganda systematica entre os jovens, mostrando o perigo da congestão universitaria, que constitue, diz elle, uma ameaça permanente. 
A nota é rica em algarismos, e deixa assombrado o leitor deante das conclusões que, com uma exactidão mathematica, tira o mestre das estatisticas com que joga e argumenta. Mas essa propaganda proposta por Nitti, parece-me muito pouco efficaz. Ha, digo eu, um bom numero de jovens que julgam ser o titulo que buscam um simples ornato, esquecidos de que, mais tarde, poderão, mudadas as suas circumstancias economicas, vir a precisar de ganhar, com o suor do rosto, o pão quotidiano. Outros ha, accrescenterei, que entendem que serão do numero dos mais afortunados. a esperança embala a todos, aliás não haveria quem comprasse bilhetes de loteria. Outros, penso, não querem sujeitar-se, em razão dos preconceitos sociaes, ao estudo de artes mais modestas. Pouco confio pois na propaganda.

O imposto sobre o rendimento das profissões liberaes a cujo proposito escreveu Nitti a admiravel nota com que estou a occupar-me, tambem adoptado no Brasil (L. 4440 de 31 de Dezembro de 1921 art. $6 \oint$ unico e D. 15569 de 29 de Julho de 1922), é medida de evidente inefficacia, e só explicavel por procurarem sempre os governos pretextos para novos impostos.

Darei minha opinião sobre o unico processo que me parece de resultado no nosso meio

\section{A LIMITAÇÃO FORÇADA}

Zombou o grande Alfredo Palacios da medida adoptada no Brasil para restricção do numero dos que se dedicam ás profissões liberaes. Pela fórma por que foi instituida essa limitação é innegavel a procedencia da critica do illustre professor. Si porém houver certas modificações no modo de selecção dos candidatos á matricula, o remédio se me afigura de resultado proveitosissimo. Não se deve deixar ao director do estabelecimento a fixação do numero de alumnos a serem recebidos na faculdade, e sim o determinar préviamente em lei, tendo o legislador deante de si as necessidades 
do paiz, após cuidadosa investigação a tal respeito. Passo a indicar a melhor maneira da escolha, em minha opinião. $\mathrm{Ha}$, nas faculdades brasileiras, o exame vestibular. Nelle já se pode notar quaes os rapazes em condições de brilhantemente figurar na carreira das letras. Pois bem! Constituida a banca examinadora, como o é, com um elevado numero de professores, votem estes, por escrutinio secreto, attribuindo graus numericos para ser calculada uma média para cada alumno examinado. Os que conseguirem mais alta média serão os unicos do $1.0^{\circ}$ anno. Os alumnos que não alcançaram uma certa média, guardado sempre o processo do escrutinio secreto, serão excluidos. Esta 2. ${ }^{\mathrm{a}}$ prova não passa de um aperfeiçoamento do que existe hoje: sabido é que, no fim do 1..$^{\circ}$ anno, ha sempre mais severidade do que em qualquer outro exame, porque pode o estudante mudar de carreira sem grande perda de tempo, só tendo cursado um anno na Faculdade.

Taes são, em meu modesto sentir, as unicas medidas adoptaveis. Estas são realmente efficazes.

Cuidado porém com a entrada de profissionaes estrangeiros. O exame de habilitação, sempre com votação por escrutinio absolutamente secreto, dará o meio de ser cohibido este mal.

Não se esqueçam os leitores de que foi o escrutinio absolutamente secreto, nas defesas de theses, que fez que 0 Brasil deixasse de ser um paiz de doutores, sendo somente a terra dos. bachareis. que se intitulam doutores.

Jỗo ARRUDA. 